\title{
Deacetylation of per-acetatylated glycopyranosides : An overall pattern for acidic catalyzis
}

\section{Nasibullin, R. T.}

2019-05-16

Nasibullin , R T, Valiev , R R , Faiskanova , K M , Stepanova , E , Cherepanov , V N , Filimonov , V D \& Sundholm , D 2019 , ' Deacetylation of per-acetatylated glycopyranosides

: An overall pattern for acidic catalyzis ' , Chemical Physics Letters , vol. 723 , pp. 123-127 . https://doi.org/10.1016/j.

http://hdl.handle.net/10138/328267

https://doi.org/10.1016/j.cplett.2019.03.022

cc_by_nc_nd

acceptedVersion

Downloaded from Helda, University of Helsinki institutional repository.

This is an electronic reprint of the original article.

This reprint may differ from the original in pagination and typographic detail.

Please cite the original version. 


\title{
Deacetylation of per-acetatylated glycopyranosides: an overall pattern for acidic catalyzis
}

R. T. Nasibullin ${ }^{1}$, R. R. Valiev ${ }^{1,2}$, K.M. Faiskanova ${ }^{2}$, E. V. Stepanova ${ }^{2 *}$, V. N. Cherepanov ${ }^{1}$, V.D. Filimonov ${ }^{3}$, D. Sundholm ${ }^{4}$

${ }^{1}$ Tomsk State University, Lenin Avenue 36, Tomsk 634050, Russia

${ }^{2}$ Research School of Chemistry \& Applied Biomedical Sciences, National Research Tomsk Polytechnic University, Lenin Avenue 30, Tomsk 634050, Russia

${ }^{3}$ The Kizhner Research Center, National Research Tomsk Polytechnic University, 30 Lenin Avenue, Tomsk 634050, Russia

${ }^{4}$ University of Helsinki, Department of Chemistry, P.O. Box 55 (A.I. Virtanens plats 1), FIN00014 University of Helsinki, Finland

*Corresponding author.E-mail addresses: glycoside.m@gmail.com,eline_m@mail.ru(E.V. Stepanova).

\begin{abstract}
Partially acetylated arylglycosides are not only useful building blocks in syntheses, but they are also substantial for plant metabolism. In this work, we study the acid-catalyzed deacetylation of per-acetylated phenyl glycosides experimentally and computationally by using density functional theory (DFT) calculations. Based on quantum modeling, we design a general scheme for the stepwise acid-catalyzed deacetylation of arylglycosides per-acetates. We have studied the deacetylation reaction in solvents of different polarity and found that the activation barriers of the stepwise deacetylation mechanism increase with increasing polarity of the solvent

\section{Key words}

aryl glycosides, acid-catalyzed deacetylation, transition state modelling, activation energy calculation
\end{abstract}

\section{Introduction}


Carbohydrate chemistry usually relies on a proper utilization of protective groups. When the protective groups have been chosen correctly, the synthesis of complex oligosaccharides is relatively simple. Acetyl protective groups are extensively used in carbohydrate chemistry. They can be both easily added to sugar residues and easily removed [1,2]. When the acetyl groups are attached to the C-2 carbon of the carbohydrate, they are participating groups in the glycosylation reaction leading in most cases selectively to 1,2 -trans products $[3,4]$. They are therefore widely used for stereo-controlled glycosylation. Base catalysis is usually employed for removing the acetyl groups through the well-known Zemplen procedure (sodium methoxide in methanol) [5,6] or by using other basic reagents $[7,8]$. Nevertheless, basic conditions also remove other ester and base-labile groups [9,10] or can cause migration of the acetyl groups [11]. Acid-catalyzed deacetylation has been proven to be more selective [12] as compared with basic catalysis [1315]. HCl-catalyzed ethanolysis of per-acetates has opened a simple route to the synthesis of 2-Oacetyl aryl glycosides [16] which are important plant metabolites [17] and chemotaxonomic markers for plant families $[18,19]$. Recently we showed the use of methoxyphenyl 2-O-acetyl galactopyranoside as glycosyl acceptor in sialylation reaction [20] which gave good yield and selectivity. Such compounds also provide diverse biological activities [21,22] and can be used for drug design.

Acid-catalyzed deacetylation of carbohydrates may find larger application in organic chemistry. However, few kinetic and thermodynamic studies are available [23] although it is well-known that acetyl groups in different position of the carbohydrate lead to differences in the thermodynamic stability and reactivity. No studies have been carried out in order to elucidate the role of the polarity of reaction medium on the reaction kinetics and selectivity of the reaction. The acid-catalyzed reaction is sometimes performed in methanol [16], which is a polar solvent or in a non-polar chloroform-ethanol mixture [21]. Since arylglycosides are potential drugs, it is important to know how the acetyl groups of the arylglycosides behave in polar media, which can be considered as a rough model for tissue. Glycosylation reactions are typically carried out in 
non-polar solvents, because one-pot automated synthesis can be feasible. Reactions in both types of solvents are important for obtaining better understanding the process.

In our recent work, we modeled the first step of acid-catalyzed ethanolysis (the protonation step) and estimated the activation barrier for each acetyl group of phenyl 2,3,4,6tetra-O-acetyl glycopyranoside using the AM1 method [23]. Although the obtained results were representative, the complete picture of acidic deacetylation is not elucidated. The aim of this work is to computationally investigate the acid-catalyzed deacetylation reaction at the density functional theory (DFT) level. The role of the polarity of the solvent is assessed by using a dielectric continuum model with different polarizability engulfing the molecular system.

\section{Calculation and experimental details}

For the investigation of acid-catalyzed deacetylation, we studied the transesterification reaction of the fully-acetylated arylglycoside - phenyl 2,3,4,6-tetra-O-acetyl glucopyranoside (1) (Fig. 1) and calculated the barriers of the stepwise ethanolysis reaction for each acetyl group. The transesterification reaction at low concentrations of acids is generally accepted to proceed via $A_{A c} 2$ mechanism [24]. The initial step of the ethanolysis reaction is the nucleophilic attack of the protonated intermediate by the ethanol molecule forming the reactant complex (RC) followed by the rate-determining reaction step yielding the transition state (TS) (Fig. 1) [24,25]. We have calculated Gibbs free energies for the reactant complex and the activation barriers for the formation of the transition state.

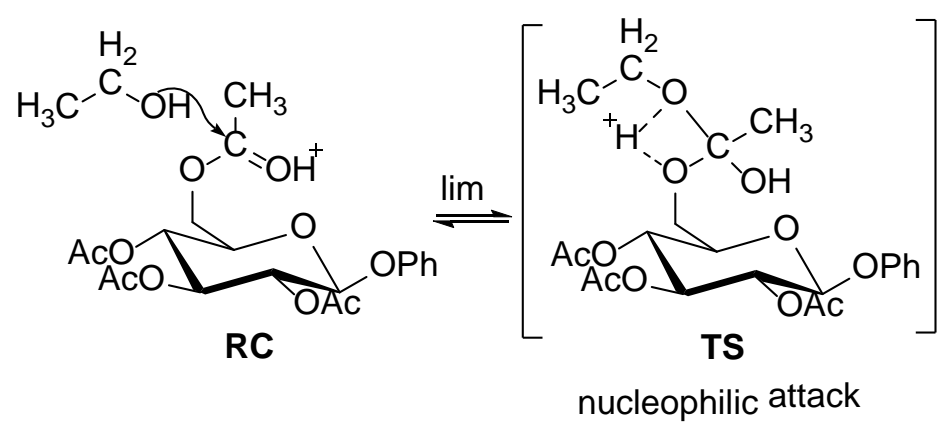

Fig 1. The rate-determining step of acid-catalyzed ethanolysis and the transition state (TS) for the 6-O-acetyl group of phenyl 2,3,4,6-tetra-O-acetylglucopyranoside (1). 


\section{Quantum chemical model}

All calculations were performed with the Gaussian 09 [26]. The molecular structures of the reactant complexes and the transition states complexes were preoptimized at the AM1 [27] semi-empirical level and further optimization was carried out at the density functional theory (DFT) [28] level using the B3LYP [29,30] hybrid functional and the 6-31G(d,p) basis set. Harmonic vibrational frequencies were calculated in order to assess whether the optimized structure corresponds to a minimum or a transition state. The calculation of the vibrational frequencies also provides zero-point vibrational energy (ZPVE), entropy contribution, and information about the thermal contribution to Gibbs free energy at a temperature of $303 \mathrm{~K}$. When it was not possible to find the transition state by using the default Berny algorithm [31], the QST2 procedure was employed [32].

The calculations were carried out for the molecular systems in the gas phase as well as in solvent by approximating it with a polarizable continuum. Three solvents were chosen to model three types of possible situations. Xylene represents non-polar solvents with a dielectric constant $(\varepsilon)$ of 2.374, dimethylsulfoxide (DMSO) is the polar solvent $(\varepsilon=46.826)$, and ethanol has moderate polarity $(\varepsilon=24.852)$. In the calculations, the influence of polarity of the solvents on the reaction pathway and reaction barriers were considered by using the self-consistent reaction field (SCRF) method and the polarizable continuum model (PCM) [33-35].

\section{Experimental Activation Energy Calculations}

Activation barriers were estimated for the ethanolysis reaction of a single 2-O-acetyl group of glycoside 2 [24] (Scheme 1). The acid-catalyzed transesterification reaction was performed in large excess of ethanol relatively to the substrate 2 . We assumed that the reaction is of first-order with respect to the 2-acetyl glycoside 2 concentration. 


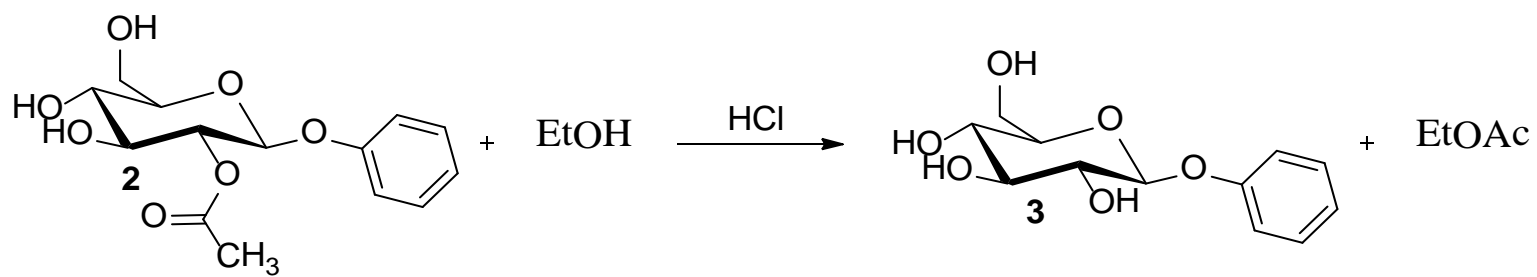

Scheme 1: The ethanolysis reaction of phenyl 2-O-acetylglucopyranoside 2.

The glycoside 2 concentration was measured using HPLC, which was carried out with an Agilent Compact LC that has a $150 \times 4.6 \mathrm{~mm}$ Eclipse Plus C-18 $(5 \mu \mathrm{m})$ column, which was eluted with a gradient of $\mathrm{H}_{2} \mathrm{O}-\mathrm{CH}_{3} \mathrm{CN}$ containing $0.1 \%$ trifluoroacetic acid from $0 \%$ to $100 \% \mathrm{CH}_{3} \mathrm{CN}$ in 20 min and a flow rate of $1 \mathrm{~mL} / \mathrm{min}$. The probe volume was $20 \mu \mathrm{L}$. UV detection was performed at $220 \mathrm{~nm}$. The calibration curve i.e., the dependence of the peak area on the concentration was prepared for the concentrations $0.25 \mathrm{mg} / \mathrm{mL}(0.84 \mathrm{M}), 0.5 \mathrm{mg} / \mathrm{mL}(1.68 \mathrm{M})$ and $1 \mathrm{mg} / \mathrm{mL}(3.35$ M).

The $0.5 \mathrm{ml}$ ampoule with a screw cap was filled with 2-O-acetyl glucoside 2 (10 mg, $33.5 \mu \mathrm{mol}$ ) and the mixture of EtOH $(12.5 \mu \mathrm{L}, 217 \mu \mathrm{mol})$, the examined solvent $(75 \mu \mathrm{L})$, and $\mathrm{HCl} 36 \%(9$ $\mu \mathrm{L}, 90 \mu \mathrm{mol}$ ) yielding a total $\mathrm{HCl}$ concentration of $0.9 \mathrm{M}$. The ampoule was closed tightly and thermostated at $30{ }^{\circ} \mathrm{C}, 40^{\circ} \mathrm{C}$ or $50^{\circ} \mathrm{C}$. At pre-selected times, a sample of $2 \mu \mathrm{L}$ was taken using 5 $\mu \mathrm{L}$ syringe, quenched with $150 \mu \mathrm{L}$ of a 1:1 acetonitrile - water mixture and $50 \mu \mathrm{L}$ of a $\mathrm{NaHCO}_{3}$ solution. The sample was analyzed by HPLC three times and the average peak area was calculated. The concentrations of compound $\mathbf{2}$ in the reaction mixture were determined from the calibration curve. The fit of the experimental data to the expression for first-order reactions was satisfactory for all the samples. The reaction rate constants $k$ at each temperature were estimated from the slope of the line in the logarithmic plot of the glycoside 2 concentration as a function of time. The rate constants that were obtained from different series of experiment with same experimental conditions could be reproduced within a 9\% inaccuracy. The activation energies for the reaction in different solvent were estimated using Arrhenius plots using rate constants measured at three temperatures (Fig. 2). 


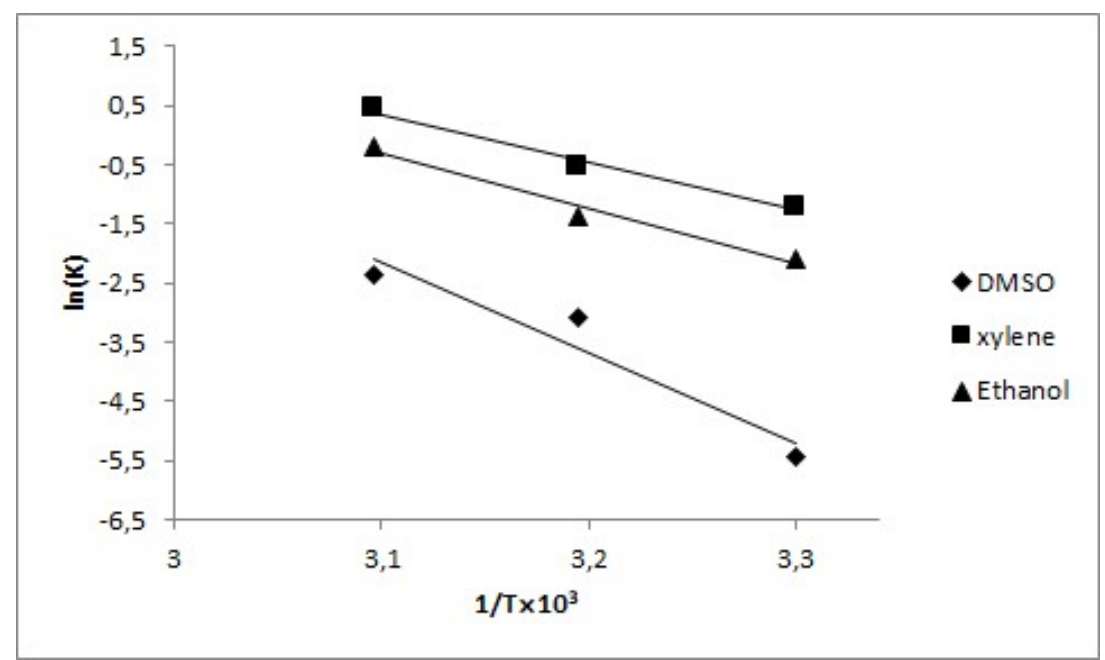

Fig 2. Arrhenius plots for the ethanolysis reaction of the 2-O-acetyl group of phenyl 2-O-acetyl

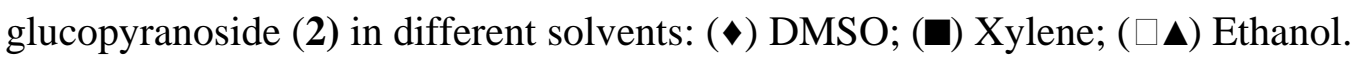

\section{Result and discussion}

The mechanism of the ethanolysis reaction involves formation of $\mathbf{R C}$ from the protonated glycoside and an ethanol molecule reacting to the TS as shown in Fig. 1. The optimized molecular structures for RC and TS of the ethanolysis reaction at O-2 of 2,3,4,6-tetra-O-acetyl glucoside $\mathbf{1}$ are shown in Fig. 3.
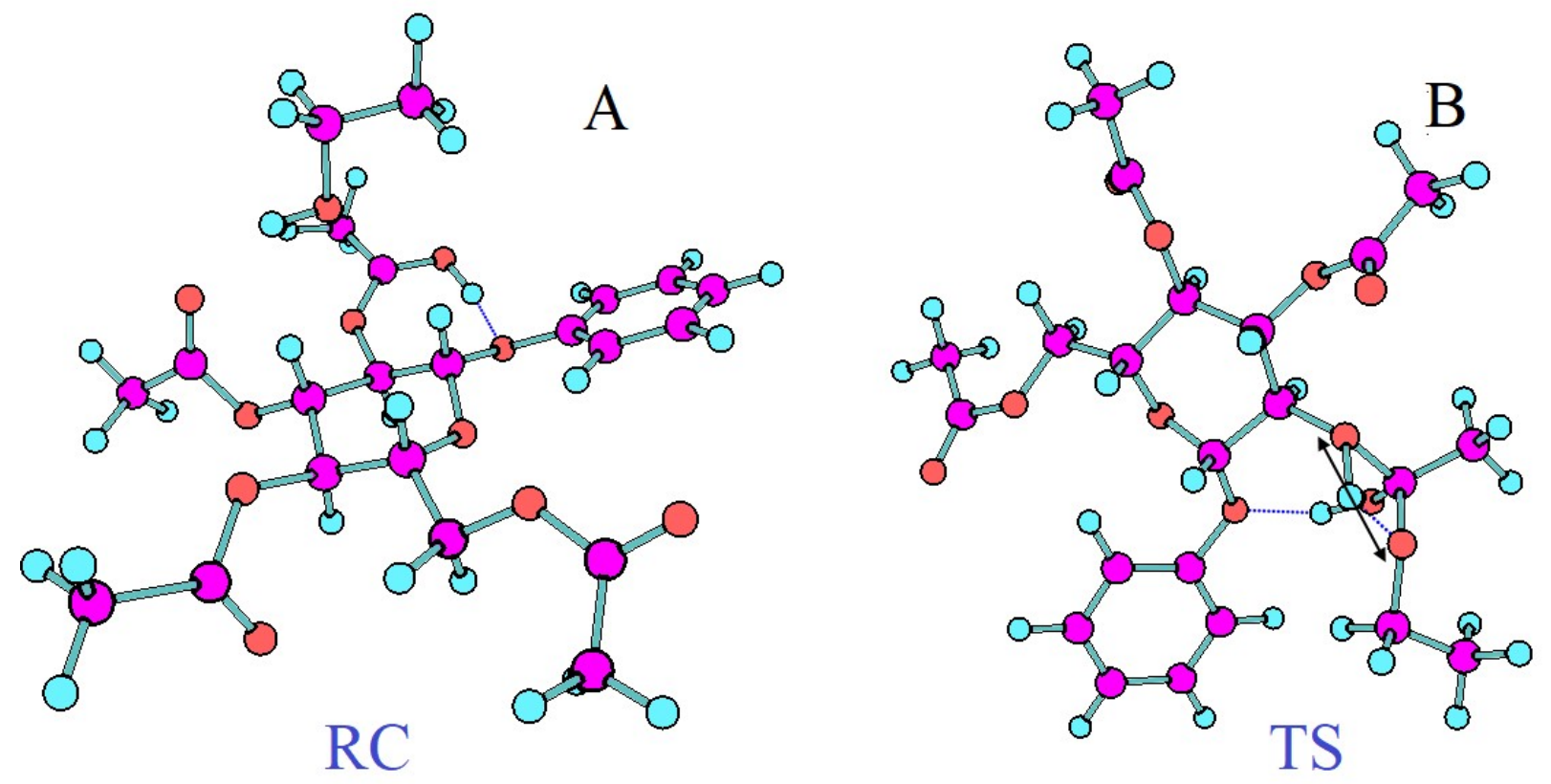
Fig 3. The optimized molecular structures of 2,3,4,6-tetra-O-acetyl glucoside $\mathbf{1}$ and the transition state of the ethanolysis reaction of the O-2 acetyl group: (A) reactant complex RC; (B) transition state TS. The black arrow shows the imaginary frequency that corresponds to transition of the proton from the ethanol oxygen to the glucose O-2.

The total energies of the reactant complex (RC) and the transition state (TS) of the ethanolysis reaction at the different glucose oxygens were calculated. The ethanolysis reaction of the fully acetylated glycoside $\mathbf{1}$ was divided into four steps denoted with lowercase letters "a,b,c,d“ in Table 1, Fig. 4 and Scheme 2. Each reaction step involves the reaction of one acetyl group. The reaction proceeds step by step involving the reaction product of previous step by removal of one of the remaining acetyl group. The nucleophilic attack by ethanol is studied in step "a” for each of the four acetyl groups of 2,3,4,6-tetra-O-acetyl glucoside 1. In step "b”, each of the three remained acetyl groups of the intermediate 2,3,4-tri-O-acetyl glucoside $\mathbf{4}$ is studied; step "c" is for the ethanolysis of each acetyl group of 2,4-di-O-acetyl glucoside 5 and the final "d" step is for ethanolysis of a single 2-O-acetyl group of glucoside 2. The stepwise reaction mechanism and the notation is shown in Scheme 2. Cartesian coordinates of the atoms of the optimized structures are given in the Supplementary data.

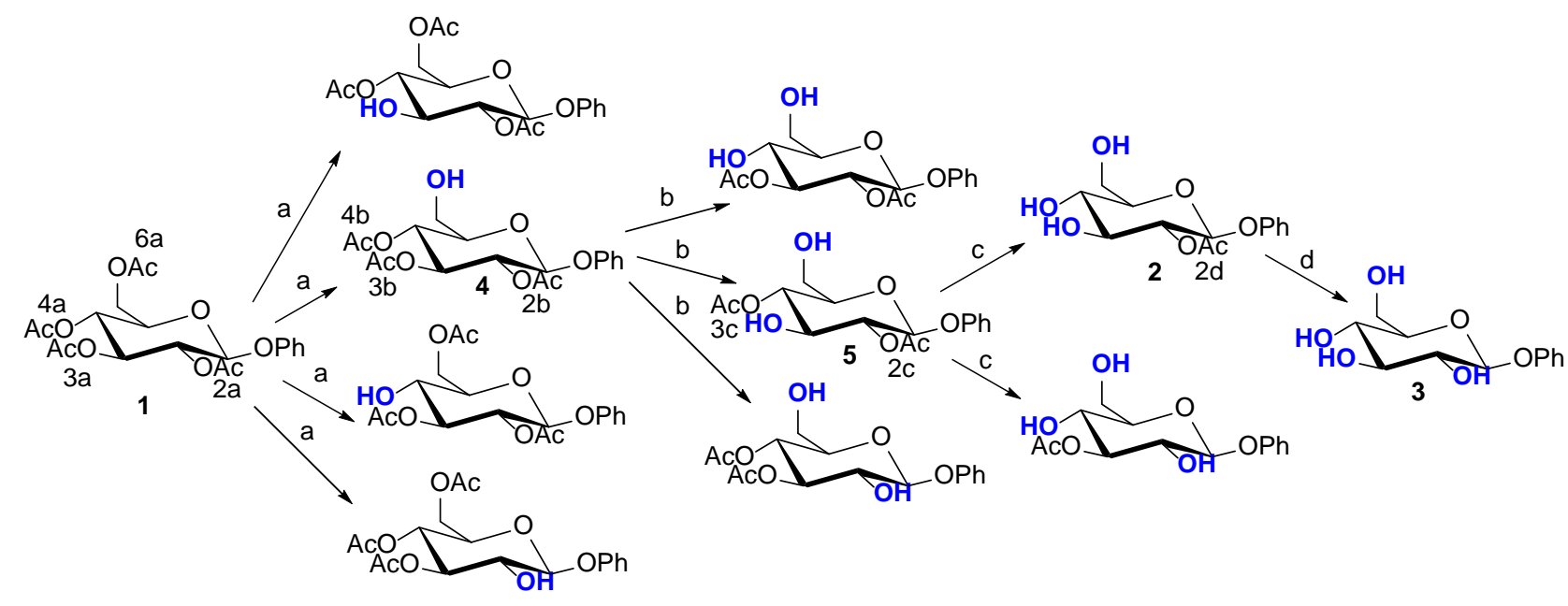


Scheme 2. The reaction scheme of the stepwise addition of acetyl groups in the acid-catalyzed ethanolysis of per-acetylated phenyl glycoside 1. The numbering of the acetyl groups is used in the energy diagram in Fig. 4.

The calculations yielded activation barriers for each step of the stepwise ethanolysis in three solvents of different polarity (Table 1). The obtained reaction barriers agree with available experimental data. The height of the activation barriers depends on the solvent, whereas the reaction mechanism remains the same regardless of the used solvent.

Table 1. Calculated activation barriers (in $\mathrm{kcal} / \mathrm{mol}$ ) of the ethanolysis reaction of each acetyl group are compared with experimental data.

\begin{tabular}{|c|c|c|c|c|c|c|c|}
\hline \multirow[b]{2}{*}{ Entry } & \multirow[b]{2}{*}{ Step } & \multirow{2}{*}{$\begin{array}{c}\text { Substrate, } \\
\text { phenyl } \\
\text { glycoside }\end{array}$} & \multirow{2}{*}{$\begin{array}{l}\text { Acetyl } \\
\text { group } \\
\text { reacted }\end{array}$} & \multicolumn{4}{|c|}{$\mathrm{E}_{\mathrm{a}}$} \\
\hline & & & & $\begin{array}{c}\text { Gas } \\
\text { phase }\end{array}$ & Xylene & Ethanol & DMSO \\
\hline 1 & 2 & 3 & 4 & 5 & 6 & 7 & 8 \\
\hline 1 & \multirow{4}{*}{$\mathrm{a}$} & \multirow{4}{*}{$\begin{array}{c}\text { 2,3,4,6-tetra- } \\
\text { O-acetyl (1) }\end{array}$} & $\mathrm{O}-2$ & 32.06 & 30.18 & 29.18 & 29.07 \\
\hline 2 & & & O-3 & 21.31 & 18.62 & 15.37 & 15.14 \\
\hline 3 & & & $\mathrm{O}-4$ & 33.88 & 32.79 & 31.67 & 31.55 \\
\hline 4 & & & O-6 & 7.79 & 7.18 & 5.9 & 5.81 \\
\hline 5 & \multirow{3}{*}{ b } & \multirow{3}{*}{$\begin{array}{l}\text { 2,3,4-tri-O- } \\
\text { acetyl (4) }\end{array}$} & $\mathrm{O}-2$ & 32.86 & 29.12 & 27.38 & 27.19 \\
\hline 6 & & & $\mathrm{O}-3$ & 18.56 & 16.79 & 13.77 & 13.61 \\
\hline 7 & & & $\mathrm{O}-4$ & 22.29 & 24.04 & 27.32 & 27.58 \\
\hline 8 & \multirow[t]{2}{*}{ C } & \multirow{2}{*}{$\begin{array}{l}\text { 2,4-di-O- } \\
\text { acetyl (5) }\end{array}$} & $\mathrm{O}-2$ & 31.88 & 31.19 & 30.18 & 30.07 \\
\hline 9 & & & $\mathrm{O}-4$ & 18.58 & 16.64 & 13.85 & 13.61 \\
\hline 10 & d & 2-O-acetyl (2) & $\mathrm{O}-2$ & 14.46 & 18.30 & 22.85 & 28.70 \\
\hline 11 & d & $\begin{array}{l}\text { 2-O-acetyl (2) } \\
\text { experimental }\end{array}$ & $\mathrm{O}-2$ & - & $15.8 \pm 1.7$ & $20.1 \pm 1.8$ & $29.8 \pm 0.5$ \\
\hline
\end{tabular}

The calculations show that the acetyl groups at O-2 and O-4 of 2,3,4,6-tetra-O-acetyl glucoside 1 have the highest reaction barrier for at the first ("a”) step in each of the studied solvents. The activation barrier for O-2 acetyl group reaction is lower by $1.82 \mathrm{kcal} / \mathrm{mol}$ than for acetyl group at 
O-4 in gas phase. The same trend is obtained in the cases of other considered solvents. The acetyl group at O-6 has the lowest activation barrier and consequently highest reactivity in the studied solvents implying that the O-6 acetyl group reacts 2-4.5 times faster than any other acetyl group in “a” step. 2,3,4-tri-O-acetyl is the first intermediate product $\mathbf{4}$ (Scheme 2). The latter is in good agreement with the known fact that the primary alcohols are more reactive than secondary alcohols [23]. For the next step "b”, we modeled the ethanolysis reaction of each acetyl group of triacetate 4 (Scheme 2). In step “b”, the acetyl group at O-3 has the highest reactivity for all solvents. The O-3 acetyl group cleavage leads to the second intermediate, which is 2,4-di-O-acetyl glucoside 5 that reacts in step “c”. In xylene, the acetyl group at O-4 has also a high reactivity leading to a reaction branch of the stepwise reaction that we have not considered. In step "c", the activation barrier for O-2 acetyl group is 13.30-16.46 kcal/mol higher than for the acetyl group at O-4 in gas phase and in the studied solvents indicating that the 2-O-acetyl glucoside $\mathbf{2}$ is the most probable product of the "c" step, which agrees well with our previous synthetic studies where we prepared 2-O-acetyl aryl glycosides with different phenolic aglycones [24]. Step "d" is the ethanolysis of the last acetyl group at O-2. We were also able to estimate activation barrier experimentally for step “d” (Table 1, entry 11). Relative potential energy profiles of the calculated reactions are shown in Fig. 4 for gas phase and in Fig. S1 (see Supplementary data) for other considered solvents. The calculations show that the general deacetylation reaction pathway is independent of the polarity of the employed solvent, which also allows us define a general reaction scheme of the stepwise deacetylation reaction of peracetyl glycosides. The reaction pathways obtained in the quantum-chemical calculations are shown in Scheme 2. The obtained scheme is in good agreement with experimental data. Thus, the deacetylation reaction of fully-protected glucoside $\mathbf{1}$ yield mixed products if stopped at reaction times which correspond to steps “a”, "b” or “c” while at higher reaction time which correspond to “d” step, experimental work was capable of yielding a single product 2-O-acetyl glucoside 2 . 


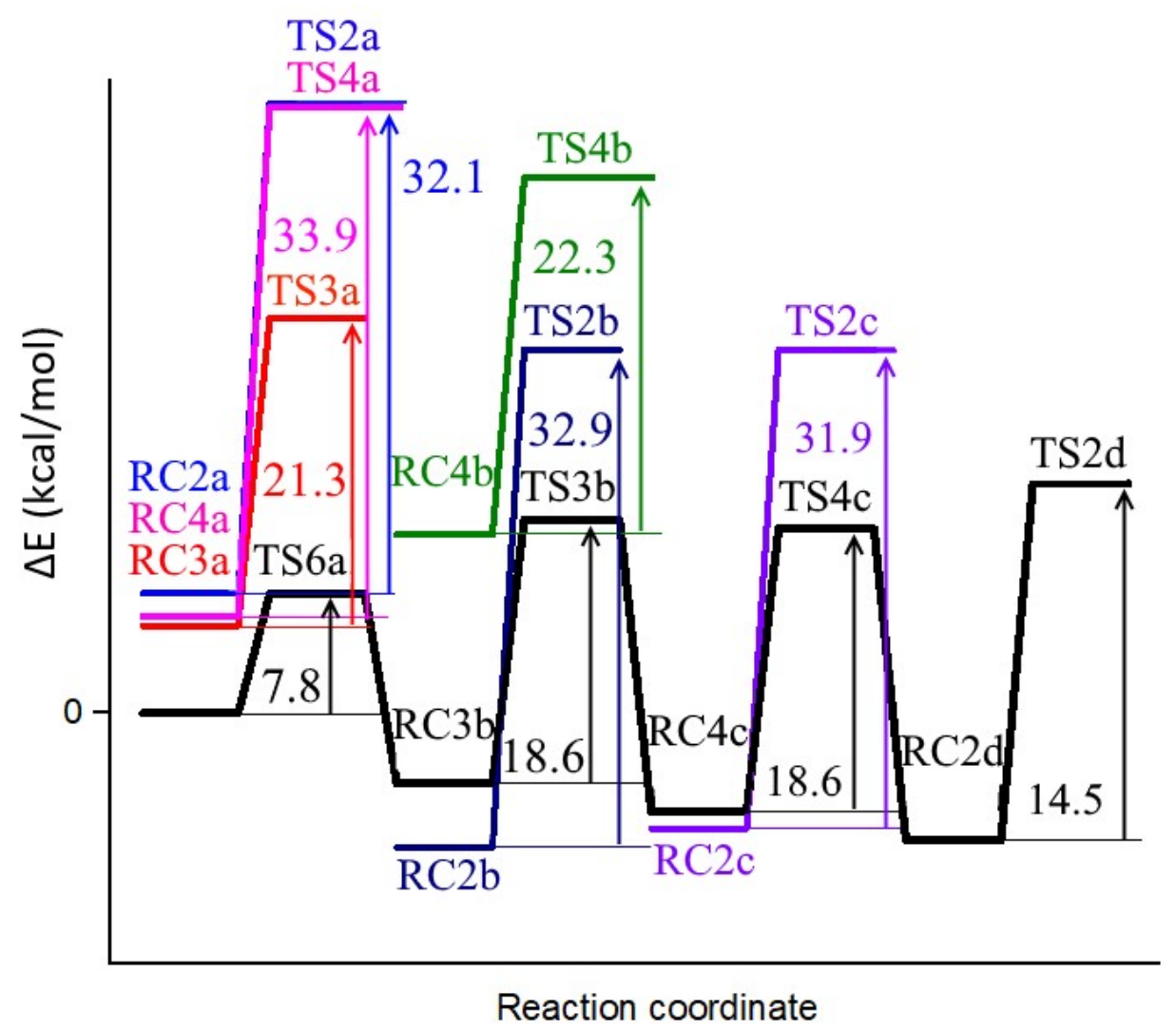

Fig 4. Relative energy profile for the stepwise ethanolysis of 2,3,4,6-tetra-O-acetyl glucoside $\mathbf{1}$ in gas phase based on the mechanism proposed in Scheme 2. The energy barriers are given in $\mathrm{kcal} / \mathrm{mol}$. The numbers after $\mathbf{R C}$ or $\mathbf{T S}$ in the notation indicate the reacting acetyl group and the lowercase letters indicate the reaction step.

The dependence of the activation barrier of the ethanolysis reaction of the O-2 acetyl group of 2 on the dielectric constant of the solvent (Fig. 5) shows that the activation barrier for deacetylation reaction increases with increasing polarity of the solvent. The calculated values are in qualitative agreement with the experimental results. The difference between calculated and measured activation barriers is $0.6-0.95 \mathrm{kcal} / \mathrm{mol}$, which is of the same size as obtained in previous studies [36,37]. The presence of ethanol in xylene and in DMSO can influence the experimentally estimated activation energies. However, the general trend obtained for the experimental activation energies agrees well with calculated results. 


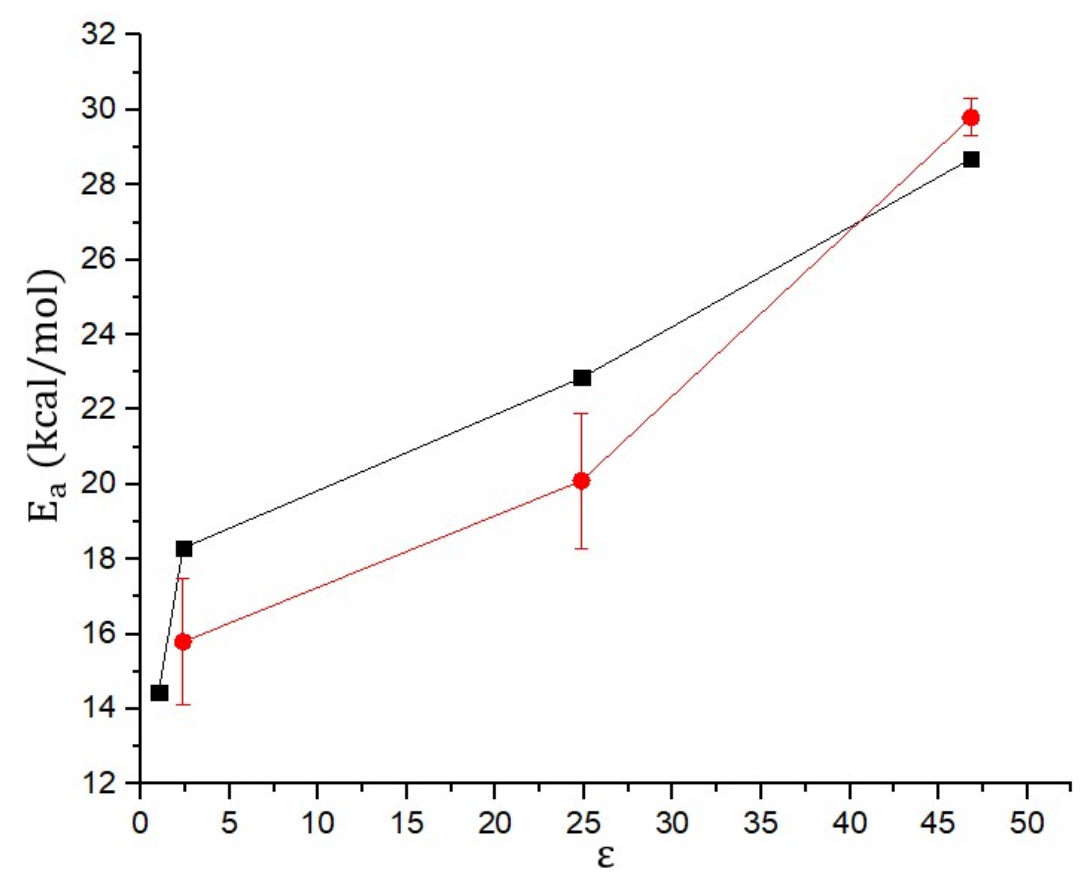

Fig 5. The dependence of activation barrier on the solvent polarity: $(\bullet)$ experimental data; (ם) calculated at DFT B3LYP/6-31G(d,p).

\section{Conclusions}

The acid-catalyzed deacetylation of per-acetylated phenyl glycosides has been studied experimentally as well as computationally by using DFT calculations. The calculations suggest that the reactivity of the acetyl groups of per-acetylated glucopyranosides differs, which leads to a stepwise reaction that forms 2-O-acetyl aryl glycosides. The calculations suggest that the reaction mechanism is independent of the polarity of the solvent, whereas the activation barriers of the stepwise deacetylation mechanism generally increase with increasing polarity of the solvent. The stepwise acid-catalyzed deacetylation mechanism shown in Scheme 2 generally holds for aryl $\beta$-gluco- and galactopyranosides bearing different substituents in the aglycone.

\section{Acknowledgements}

Authors would like to thank TPU Shared Knowledge Center - Physical and Chemical Methods for the opportunity to conduct HPLC experiments. Quantum chemical calculations were carried out with the support of the Tomsk State University Competitiveness Improvement Programme grant (N8.1.03.2017) and the Academy of Finland through projects 275845 and 297304. The reported kinetic study studies were funded by RFBR according to the research 
project № 18-33-00365 and Tomsk Polytechnic University Competitiveness Enhancement Program grant.

\section{Supplementary data}

Supplementary data section contains the Cartesian coordinates for all calculated structures. Supplementary data associated with this article can be found, in the online version, at doi:10.1016/j.carres.xxxxxx.

\section{References}

1 P.G. Wuts, T.W. Greene, Greene's protective groups in organic synthesis; John Wiley \& Sons (2006).

2 P.K. Kancharla, T. Kato, D. Crich, J. Am. Chem. Soc. 136 (2014) 5472-5480.

3 J. Guo, X.S. Ye, Molecules 15 (2010) 7235-7265.

4 Y. Yang, X.Zhang, B. Yu, Nat. Prod. Rep. 32 (2015) 1331-1355.

5 G. Zemplén, E. Pacsu, Ber. Dtsch. Chem. Ges. 62 (1929) 1613-1614.

6 Z. Wang, Comprehensive Organic Name Reactions and Reagents; John Wiley \& Sons, Inc. (2010).

7 B. Ren, M. Wang, J. Liu, J. Ge, X. Zhang, H. Dong, Green Chem. 17 (2015) 1390-1394.

8 S. Zhou, J. Zemlicka, Nucleos. Nucleot. Nucl. 26 (2007) 391-402.

9 G.Zemplen, R. Bognar, G. Pongor, Acta Chim. Hung. Tomus. 19 (1959) 285-293.

10 C. Costachel, P.J. Sansonetti, L.A. Mulard, J. Carbohydr. Chem. 19 (2000) 1131-1150

11 M.U. Roslund, O. Aitio, J. Wärnå, H. Maaheimo, D. Y. Murzin, R. Leino, J. Am. Chem. Soc. 130 (2008) 8769-8772. C8-C11.

12 N.É. Byramova, M.V. Ovchinnikov, L.V. Backinowsky, N.K. Kochetkov, Carbohydr. Res. 124 (1983)

13 A.K. Pathak, C.K. Yerneni, Z. Young, V. Pathak, Org. lett. 10 (2008) 145-148.

14 M.L. Gening, Y.E. Tsvetkov, G.B. Pier, N.E. Nifantiev, Carbohydr. Res. 342 (2007) 567-575.

15 O.N. Yudina, M.L. Gening, Y.E. Tsvetkov, A.A. Grachev, G.B. Pier, N.E. Nifantiev, Carbohydr. Res. 346 (2011) 905-913.

16 E.V. Stepanova, M.L. Belyanin, V.D. Filimonov, R.R. Valiev, M. Gruner, V.O. Rogachev, Carbohydr. Res. 409 (2015) 36-40.

17 C.S. Kim, L. Subedi, K.J. Park, S.Y. Kim, S.U. Choi, K.H. Kim, K.R. Lee, Fitoterapia 106 (2015) 147-

152.

18 G.A. Boeckler, J. Gershenzon, S.B. Unsicker, Phytochemistry 72 (2011) 1497-1509.

19 L. Nybakken, R. JulkunenTiitto, Physiol. Plant. 147 (2013) 465-476.

20 M.O. Nagornaya, A.V. Orlova, E.V. Stepanova, A.I. Zinin, T.V. Laptinskaya, L.O. Kononov, Carbohydr. Res. 470 (2018) 27-35.

21 H. Yang, S.H. Lee, S.H. Sung, J. Kim, Y.C. Kim, Planta med. 79 (2013) 78-82.

22 N. Foerster, C. Ulrichs, M. Zander, R. Kätzel, I. Mewis, Gesunde. Pflanzen. 61 (2009) 129-134.

23 Stepanova, M.O. Nagornaya, V.D. Filimonov, R.R. Valiev, M.L. Belyanin, A.K. Drozdova, V.N. Cherepanov, Carbohydr. Res. 458 (2018) 60-66.

24 K. Yates, R.A. McClelland. J Am Chem Soc. 89 (1967) 2686-2692.E.V.

25 N.B. Librovich, E.G.Tarakanova, Dokl. Akad. Nauk 410 (2006) 357-360.

26 M. Frisch, G. Trucks, H. Schlegel, G. Scuseria, M. Robb, J. Cheeseman, G. Scalmani, V. Barone, B. Mennucci, G. Petersson, H. Nakatsuji, M. Caricato, X. Li, H. Hratchian, A. Izmaylov, J. Bloino, G. Zheng, J. Sonnenberg, M. Hada, M. Ehara, K. Toyota, R. Fukuda, J. Hasegawa, M. Ishida, T. Nakajima, Y. Honda, O. Kitao, H. Nakai, T. Vreven, J. Montgomery Jr., J. Peralta, F. Ogliaro, M. Bearpark, J. Heyd, E. Brothers, K. Kudin, V. Staroverov, R. Kobayashi, J. Normand, K. Raghavachari, A. Rendell, J. Burant, S. Iyengar, J. Tomasi, M. Cossi, N. Rega, J. Millam, M. Klene, J. Knox, J. Cross, V. Bakken, C. Adamo, J. Jaramillo, R. Gomperts, R. Stratmann, O. Yazyev, A. Austin, R. Cammi, C. Pomelli, J. Ochterski, R. Martin, K. Morokuma, V. Zakrzewski, G. Voth, P. Salvador, J. Dannenberg, S. Dapprich, A. Daniels, O. Farkas, J. Foresman, J. Ortiz, J. Cioslowski, D. Fox, Gaussian 09, Revision A.02, Gaussian, Inc., Wallingford CT (2009).

27 M.J.S. Dewar, E.G. Zoebisch, E.F. Healy, J. Am. Chem. Soc. 107 (1985) 3902-3909.

28 R.O. Jones, Rev. Mod. Phys. 87 (2015) 897-923.

29 A.D. Becke, J. Chem. Phys. 98 (1993) 5648-5652.

30 C. Lee, W. Yang, R.G. Parr, Phys. Rev. B. 37 (1988) 785.

31 X.Li,; M.J. Frisch, J. Chem. Theory Comput. 2 (2006) 835-839.

32 C. Peng, H.B. Schlegel, Israel J. Chem. 33 (1993) 449-454. 
33 S. Miertus, E. Scrocco, J. Tomasi, Chem. Phys. 55 (1981) 117-129.

34 S. Miertus, J. Tomasi, Chem. Phys. 65 (1982) 239-245.

35 J. Tomasi, B. Mennucci, Chem. Rev. 105 (2005) 2999-3093.

36 K.M. Uddin, C.J. Flinn, R.A. Poirier, Comp. Theor. Chem. 1027 (2014) 91-102.

37 I. Delso, A. Melicchio, A. Isasi, T. Tajero, P. Merino, Eur. J. Org. Chem. 25 (2013) 5721-5730. 